\title{
Editorial
}

\section{Ecosystem Services, Green Infrastructure and Spatial Planning}

\author{
Corrado Zoppi \\ Department of Civil and Environmental Engineering and Architecture, University of Cagliari, Via Marengo 2, \\ 09123 Cagliari, Italy; zoppi@unica.it
}

Received: 9 May 2020; Accepted: 26 May 2020; Published: 27 May 2020

check for updates

\begin{abstract}
Ecosystem services and green infrastructure do not appear to inform spatial policies and plans. National governments hardly identify their ecological networks or make an effort to integrate them into their spatial policies and plans. Under this perspective, an important scientific and technical issue is to focus on preserving corridors for enabling species mobility and on achieving connectivity between natural protected areas. In this respect, this Special Issue takes a step forward insofar as it aims at proposing a theoretical and methodological discussion on the definition and implementation of ecological networks that, besides guaranteeing wildlife movements, also provide a wide range of ecosystem services. The social and economic profile of this question is also relevant since in the long run, savings in public spending (e.g., due to the reduced need for grey infrastructures aiming at contrasting soil erosion or at managing flood risk), savings in private spending (e.g., on water treatment costs) and the potential creation of green jobs are foreseeable. Moreover, indirect and less easily quantifiable social and health benefits (e.g., due to improved natural pollution abatement) are likely to occur as well.
\end{abstract}

Keywords: ecological corridors; ecosystem services; green infrastructure; landscape connectivity; landscape fragmentation; Natura 2000 Network

With regards the United Nations Convention on Biological Diversity, ratified by Italy by Law no. 1994/124, an ecosystem is "a dynamic complex of plant, animal and micro-organism communities and their nonliving environment interacting as a functional unit". Ecosystem goods and services, univocally defined as "ecosystem services", represent the benefits human populations derive, directly or indirectly, from ecosystem functions [1].

When trying to assess the ecosystem services of natural resources, the usual vision is always based on qualitative approaches. The importance of environmental services is generally recognized and as well as how much they are worth protecting and restoring. However, it is very difficult to compare the costs, which can be easily revealed in monetary terms, to the benefits, which are always in the abstract world of ideas. Actually, it is impossible to compare apples to oranges. It would be of huge utility for planning and managing to have tools that bridge this gap [2].

It has to be emphasized that the strategic environmental assessment (SEA) of management plans (MPs) for Natura 2000 sites has to be regarded as an assessment exercise concerning not merely a single node of the ecological network (that is, a single Natura 2000 site), but rather the network as a whole. SEA is intrinsically connected to sustainability because it establishes environmental protection-related objectives, and therefore it acts as a sustainability-oriented plan which becomes part of the planning process itself [3]. This is of particular importance with reference to the definition of conservation measures, including the preparation of MPs, as SEA can help integrate sustainability within MP objectives and can be regarded as a real and effective learning path for the administrations in charge of Natura 2000 sites [4]. Within the SEA, a fundamental issue is the assessment of the restoration of ecosystem services [5]. 
In the Communication from the Commission to the European Parliament, the Council, the European Economic and Social Committee and the Committee of the Regions (COM (2013) 249 final), a working definition of green infrastructure (GI) is proposed as follows: "A strategically planned network of natural and semi-natural areas with other environmental features designed and managed to deliver a wide range of ecosystem services. It incorporates green spaces (or blue if aquatic ecosystems are concerned) and other physical features in terrestrial (including coastal) and marine areas. On land, GI is present in rural and urban settings" [6]. Moreover, the Commission puts in evidence how and how much the issue of GI relates to the Network of Sites of community importance (SCIs), Special areas of conservation (SACs) and Special protection areas (SPAs): "The work done over the last 25 years to establish and consolidate the network means that the backbone of the EU's GI is already in place. It is a reservoir of biodiversity that can be drawn upon to repopulate and revitalize degraded environments and catalyze the development of GI [7]. This will also help reduce the fragmentation of the ecosystem, improving the connectivity between sites in the Natura 2000 Network and thus achieving the objectives of Article 10 of the Habitats Directive" [8].

Hence, it is evident that the definition of GI is strictly connected to the category of ecosystem services. Moreover, it has to be a planned network [9]. Spatial planning, at the regional and urban levels, is an important and effective perspective to address the complex issue of defining, implementing and managing networks of ecosystem services and GI [10].

As a consequence, GI has a decisive role in promoting the restoration of biodiversity and in reducing the fragmentation of ecosystems, and eventually, in their capability of delivering ecosystem services [11]. Therefore, a general goal of the SEA of MPs of Sites of the Natura 2000 Network can be defined in order to address the issue of the role of GI in promoting and enhancing habitat restoration and the delivery of ecosystem services [12].

A wide range of issues related to ecosystem services and GI, as important points of reference for spatial planning, related to urban and rural contexts [13], with particular reference to the definition and implementation of planning policies aimed at protecting nature and natural resources [14], are discussed in the articles of the Special Issue.

The published studies are related to four main questions, which can be highlighted as follows. A first point focuses on the different approaches to build a consistent Natura 2000 Network. As per Lai's article, outstanding differences are still in place, which generate relevant problems with regards to the completion of the establishment process of the Natura 2000 Sites. These inconsistencies can be generalized as potential hindrances concerning the implementation of the Network across the whole European Union.

A second relevant issue concerns the use of planning methodologies based on the definition of spatial policies which build on ecosystems and GI as supply sources of publicly available services in urban contexts. This theme is treated by: i. Colavitti, Floris and Serra with reference to the endowment standards of public services in urban plans; ii. Moura and Fonseca, with regards to the vulnerability of urban environments related to vegetation depletion, which can be effectively addressed through appropriate GI planning; iii. Santoro, Balena and Camarda, in relation to the comprehensive planning approach of the Master Plan of the Italian city of Bari; iv. Garau and Annunziata, with reference to the definition and implementation of a GI aimed at improving the attractiveness and livability of urban environments for children; v. Lai, Leone and Zoppi, with regards to the identification of spatial policies to support the implementation of a regional GI by enhancing its components at the local scale, represented by three urban areas of the Metropolitan City of Cagliari.

Thirdly, a clear cut research line is identified by the use of ecosystem services and GI to implement spatial policies aimed at protecting and enhancing nature, natural resources and environmental quality. The studies related to this issue are presented in the articles by: i. Scorza, Pilogallo, Saganeiti and Murgante on the features of the relationship between the protection of nature and environmental recovery concerning a Natura 2000 Site and a nationally recognized polluted site located in the Basilicata region; ii. Cialdea on the use of environmental matrices to define planning policies in a 
coastal area which surrounds the town of Termoli, in the Molise region, in the context of regional landscape planning-oriented spatial processes; iii. Floris, Gazale, Isola, Leccis, Pinna and Pira on the implementation of ecosystem services-based planning policies to define and develop the integration of the MPs of Natura 2000 Sites into the spatial regulations of marine protected areas; the proposed methodological approach is applied to the marine protected area of the Asinara Island; iv. Fallanca, Taccone and Corazziere on the identification of natural and historical heritage as fundamental ecosystem services-related features to promote local development processes based on the enhancement of environmental quality, natural capital, and historical and cultural endowment; the methodological approach is implemented into the Metropolitan City of Reggio Calabria; v. Leone and Zoppi on the definition of a methodology to support decision-making processes in the implementation of the Integrated Coastal Zone Management Protocol [15] at the local level; objectives deriving from different plans, such as coastal land use plans (CLUPs) and MPs of Natura 2000 Sites (MPs), are analyzed and compared in terms of reciprocal consistency in order to integrate their planning strategies and to identify the potentially negative impacts of CLUPs on MPs; the methodological approach is implemented into three spatial contexts of the Sulcis area, located in southwest Sardinia.

Finally, a couple of articles concern the use of ecosystem services and GI to set up spatial policies aimed at defining and implementing regional plans, which integrate objectives related to the protection of nature and natural resources as well as economic and social development goals. These studies are proposed by: i. Balletto, Milesi, Ladu and Borruso, who present a methodological approach to tourism planning based on a GI finalized to increase the tourist attractiveness of the Sardinian Sulcis area; ii. Magaudda, D'Ascanio, Muccitelli and Palazzo, who discuss the relations between agricultural production and the implementation of ecological networks and connectivity in the conceptual framework of the Common Agricultural Policy; iii. Campagna, Di Cesare and Cocco, who present an application of the geodesign methodology to a strategic planning framework related to the Metropolitan City of Cagliari, which identifies and integrates into the planning process a metropolitan GI; iv. De Pascali, Santangelo, Perrone and Bagaini, who identify some general guidelines to implement adequate relations between the supply of provisioning and regulating ecosystem services, and the decentralization process of the energy systems; v. Balletto, Milesi, Fenu, Borruso and Mundula, who target the valorization issue of military properties located in areas attractive for leisure and tourism which are made partially available to the public due to agreements between the National Defense Ministry and the local municipalities; the potential of these areas is assessed in terms of the supply of cultural and tourism-related (recreational) ecosystem services, and an analytical methodological approach is implemented with regards to a military coastal area located in southeast Sardinia.

Funding: This research was partially funded by the Research Project based on the Agreement between Dipartimento di Ingegneria Civile, Ambientale e Architettura (Department of Civil, Environmental Engineering and Architecture, DICAAR) of the University of Cagliari, Italy, and the Autonomous Region of Sardinia, Departmental Office of Environment Protection, finalized to the objectives of the Project "GIREPAM-Integrated Management of Ecological Networks through Parks and Marine Areas" (Programme INTERREG Marittimo Italy-France Maritime 2014-2020, Axis 2).

Conflicts of Interest: The author declares no conflict of interest.

\section{References}

1. Costanza, R.; Folke, C. Valuing ecosystem services with efficiency, fairness, and sustainability as goals. In Nature Services. Societal Dependence on Natural Ecosystems; Daily, G.C., Ed.; Island Press: Washington, DC, USA; Covelo, CA, USA, 1997; ISBN 1559634758.

2. Chaudhary, S.; McGregor, A.; Houston, A.; Chettri, N. The evolution of ecosystem services: A time series and discourse-centered analysis. Environ. Sci. Policy 2015, 54, 25-34. [CrossRef]

3. Geneletti, D. Reasons and options for integrating ecosystem services in Strategic environmental assessment of spatial planning. Int. J. Biodivers. Sci. Ecosyst. Serv. Manag. 2011, 7, 143-149. [CrossRef]

4. Mascarenhas, A.; Ramos, T.B.; Haase, D.; Santos, R. Ecosystem services in spatial planning and strategic environmental assessment-A European and Portuguese profile. Land Use Policy 2015, 48, 158-169. [CrossRef] 
5. Zoppi, C. Integration of conservation measures concerning Natura 2000 Sites into Marine Protected Areas regulations: A study related to Sardinia. Sustainability 2018, 10, 3460. [CrossRef]

6. Liquete, C.; Kleeschulte, S.; Dige, G.; Maes, J.; Grizzetti, B.; Olah, B.; Zulian, G. Mapping green infrastructure based on ecosystem services, and ecological networks: A pan-European case study. Environ. Sci. Policy 2015, 54, 268-280. [CrossRef]

7. Anton, C.; Young, J.; Harrison, P.A.; Musche, M.; Bela, G.; Feld, C.K.; Harrington, R.; Haslett, J.R.; Pataki, G.; Rounsevell, M.D.A.; et al. Research needs for incorporating the ecosystem service approach into EU biodiversity conservation policy. Biodivers. Conserv. 2010, 19, 2979-2994. [CrossRef]

8. Hansen, R.; Pauleit, S. From multifunctionality to multiple ecosystem services? A conceptual framework for multifunctionality in Green Infrastructure planning for urban areas. AMBIO 2014, 43, 516-529. [CrossRef] [PubMed]

9. Cannas, I.; Lai, S.; Leone, F.; Zoppi, C. Green infrastructure and ecological corridors: A regional study concerning Sardinia. Sustainability 2018, 10, 1265. [CrossRef]

10. Arcidiacono, A.; Ronchi, S.; Salata, S. Managing multiple ecosystem services for landscape conservation: A green infrastructure in Lombardy Region. Procedia Eng. 2016, 161, 2297-2303. [CrossRef]

11. Taylor-Lovell, S.; Taylor, J.R. Supplying urban ecosystem services through multifunctional green infrastructure in the United States. Landsc. Ecol. 2013, 28, 1447-1463. [CrossRef]

12. Partidário, M.R.; Gomes, R.C. Ecosystem services inclusive strategic environmental assessment. Environ. Impact Assess. Rev. 2013, 40, 36-46. [CrossRef]

13. Vallecillo, S.; Polce, C.; Barbosa, A.; Castillo, C.P.; Vandecasteele, I.; Rusch, G.M.; Maes, J. Spatial alternatives for Green Infrastructure planning across the EU: An ecosystem service perspective. Landsc. Urban. Plan. 2018, 174, 41-54. [CrossRef]

14. De Groot, R.S.; Alkemade, R.; Braat, L.; Hein, L.; Willemen, L. Challenges in integrating the concept of ecosystem services and values in landscape planning, management and decision making. Ecol. Complex. 2010, 3, 260-272. [CrossRef]

15. The Protocol on Integrated Coastal Zone Management (ICZM Protocol) to the Barcelona Convention (Council Decision 2010/631/EU) Was Ratified by the EU on September 13, 2010. The Protocol Was Adopted by the Council on December 4, 2008 (2009/89/EC). 2010. Available online: http://ec.europa.eu/environment/iczm/ barcelona.htm (accessed on 11 May 2020).

(C) 2020 by the author. Licensee MDPI, Basel, Switzerland. This article is an open access article distributed under the terms and conditions of the Creative Commons Attribution (CC BY) license (http://creativecommons.org/licenses/by/4.0/). 